\title{
Tiempo, memoria, escritura (a propósito de la narrativa chilena)
}

Time, memory, writing (regarding chilean narrative)

\author{
Mario Lillo Cabezas \\ Pontificia Universidad Católica de Chile, Facultad de Letras, Campus San Joaquín, \\ Avenida Vicuña Mackenna 4860, Macul, Santiago de Chile, Chile, \\ e-mail: mlillo@puc.cl
}

El artículo es una reflexión previa que intenta fundamentar teóricamente los problemas del tiempo, de la memoria y de la escritura presentes en la narrativa chilena posterior a 1990, por ejemplo, de Gonzalo Contreras. La carencia de espesor temporal, la memoria reprimida o silenciada y la escritura incapaz de dar cuenta del pasado son hipótesis que vertebran las reflexiones.

Palabras clave: tiempo, memoria, escritura.

This article is a theoretical reflection on the issues of time, memory and writing in the Chilean contemporary narrative after 1990, including the works of Gonzalo Contreras. The lack of time density, the repressed or silenced memory and the incapacity of writing to deal with the past are the axis of this article.

Key words: time, memory, writing.

\section{TIEMPO Y ACUMUlaCión PRECARIA DE SABERES: El ESCENARIO DEL PRESENTE}

A modo de fundamentación teórica preliminar a un estudio en torno al tiempo y a la memoria en la narrativa chilena contemporánea sobre la base de las novelas de Gonzalo Contreras y la consideración de otras sensibilidades narrativas de la década de 1990, en la primera parte abordaremos un aspecto específico de las reflexiones en torno al fenómeno histórico desarrolladas por Friedrich Nietzsche.

En estas, el filósofo alemán señala la necesidad de romper y disolver parte del pasado, pues todo pasado merece condenación dada la naturaleza violenta y débil de las cosas humanas y porque somos el resultado de generaciones anteriores, de sus aberraciones, pasiones, errores y delitos. El ser humano intenta darse a posteriori un pasado del que se querría proceder, en contraposición a aquel del cual realmente se procede. Pero ahí reside justamente el peligro: encontrar un límite en la negación del pasado (1967: 129-30). También es necesario hacer compatible esa negación con aquello que Nietzsche considera como el secreto mejor guardado de la modernidad, que consiste en que el hombre moderno no tiene nada propio, sino que a modo de sustitución de esta carencia se rellena y sobresatura de épocas, costumbres, artes, 
filosofías, religiones y conocimientos extraños, convirtiéndose así en una verdadera enciclopedia ambulante (id.: 132-3).

En lo que concierne a los protagonistas de las novelas de Gonzalo Contreras, por ejemplo, estos no serían demasiado modernos, dado que parecen actuar como seres ahistóricos, desplegando una actitud de vida que los sitúa más allá del afán de acumulación de saberes, del conocimiento de sí mismos y del mundo que los rodea, pues se los percibe concentrados en su peripecia individual y de corto alcance. En consecuencia, y para los efectos de una investigación más focalizada, sería necesario descubrir y analizar diferenciadamente el tiempo y la memoria en las distintas novelas de este y de otros novelistas chilenos de la mencionada década, puesto que a simple vista se observan diferencias de grado en la densificación narrativa del pasado con su natural corolario, la falta de espesor temporal y la carencia de memoria.

Por otra parte, la manifestación del presente como escenario primordial del acontecer, tanto físico como anímico, en las narraciones de la década puede corresponder a uno de los efectos de la precariedad de la vida cotidiana que analiza Martín Hopenhayn en Ni apocalípticos ni integrados-Aventuras de la modernidad en América Latina. En este ensayo, el filósofo habla del horizonte total [destacado nuestro] de la vida diaria en que se ha convertido el horizonte de corto plazo, justamente debido a la aceleración del cambio en todos los aspectos de la vida cotidiana. Por consiguiente, habría desaparecido de la vista y del sentido el horizonte de largo plazo en la existencia del hombre (1994: 26). En este contexto, ¿cuál podría ser la fuente del goce de la vida? Para Hopenhayn son varias estas fuentes, pero interesa destacar una, la que señala que “[E]l goce de la vida está en la liviandad de lazos. No hay un lazo firme con el futuro, con el trabajo actual, con los interlocutores del momento. Todo puede modificarse mañana y situarnos en otro presente [...] Frente a ello, dos posibilidades: o morir de provisoriedad, o hacerse pleno de ella" (id.: 28).

El análisis pormenorizado de las novelas del período señalado anteriormente podría ofrecer una respuesta tanto a este planteamiento -por lo significativas que pueden resultar sus implicancias en el ámbito afectivo de los protagonistas- como a la problematización acerca de las paradojas de la situación actual de la modernidad en el marco del subdesarrollo que detecta Hopenhayn en su estudio, paradojas que se traducen en embriaguez por amnesia y en la subsecuente fuga hacia el futuro. Desentenderse del pasado es la proclama para combatir la entropía y el estancamiento, entonces, esta sería la fórmula para evitar la inercia que lleva a la regresión en el clima cultural contemporáneo. Pero la renuncia al pasado conlleva necesariamente efectos que redundan en lo que Hopenhayn denomina "contingencia sin suelo", y que lo conducen a formular la siguiente interrogante: “QQué pasa con nuestro territorio, y cómo, a través de esta pérdida de memoria, nos replanteamos nuestro deseo de modernidad?" (ibíd.). Presumimos que esa contingencia sin suelo a la cual se refiere Hopenhayn es, precisamente, una óptica pertinente para examinar el fenómeno de carencia de espesor temporal, de proyección al futuro y de indigencia en los saberes y experiencias de vida que patentizan muchos personajes de la novelística de la época en Chile. 


\section{LA MEMORIA Y LA HISTORIA: ANTICUARIOS, MONUMENTALISTAS Y CRÍTICOS}

Una vía de entrada al problema del tiempo y de la memoria en la narrativa de 1990 en adelante consiste en averiguar de qué manera el individuo confronta el fenómeno de la historia, entendido este como uno de los depósitos institucionalizados para el acopio de las experiencias del pasado. La manera en que el hombre se relaciona con la historia es materia sobre la cual reflexionó Friedrich Nietzsche y en referencia a los temas que nos interesan distingue tres maneras de entender la historia: monumental, anticuaria y crítica:

[C]uando un hombre que desea realizar algo grande tiene necesidad del pasado, se apropia de él mediante la historia monumental; a su vez, el que persiste en lo habitual y venerado a lo largo del tiempo, cultiva el pasado como historiador anticuario; y solo aquel a quien una necesidad presente oprime el pecho y que, a toda costa, quiere librarse de esa carga, siente la necesidad de la historia crítica, es decir, de la historia que juzga y condena. ${ }^{1}$

A la luz de lo anterior, un aspecto que sería necesario dilucidar en la narrativa chilena contemporánea es el modo de configuración del relato en su sentido históricomemorialístico. Un análisis de estos aspectos suministraría datos que permitirían descubrir el mecanismo consciente o inconsciente de (posible) apropiación del pasado por parte de los respectivos hablantes implicados en las novelas, a quienes podremos eventualmente incluir dentro de la categoría de los anticuarios, monumentalistas o críticos de la historia. Apriorísticamente se puede especular en el sentido de que contemporáneos y coetáneos de la década del 90 del siglo XX no parecen sentirse depositarios de una carga respecto del pasado de la cual quisieran librarse mediante el ejercicio de una escritura que enfrenta la historia de manera crítica. Aquí no podemos dejar de señalar que, por otra parte, y desde una perspectiva global, la narrativa de los '90 emite numerosas señales de hallarse muy lejana a la tarea de tomar a su cargo el pasado de manera ya sea anticuaria o monumentalista. A partir de estas señales se percibe que no hay mucho que inventariar, celebrar o conmemorar, y en el caso específico de Gonzalo Contreras, por citar el ejemplo más claro en este sentido, la revisión preliminar de sus novelas permite detectar una carencia de sentido histórico en los protagonistas, pues si observamos detenidamente las maneras que propone Nietzsche de enfrentar la historia, se hace evidente la orfandad vital del sujeto de esta novelística en particular y acaso de toda la de la época. Y ante lo que detecta como ahistoricidad de la época moderna, dice el filósofo: "El sentimiento opuesto, el bienestar del árbol con sus raíces, la felicidad de no saberse totalmente arbitrario y fortuito, sino proceder de un pasado del que se es heredero, la flor y el fruto, y que

1 La versión en español que presentamos es de traductor desconocido y está tomada de www.elabedul.net/ Documentos/De_la_utilidad.doc. El texto original señala: "Wenn der Mensch, der Grosses schaffen will, überhaupt die Vergangenheit braucht, so bemächtigt er sich ihrer vermittelst der monumentalischen Historie; wer dagegen im Gewohnten und Altverehrten beharren mag, pflegt das Vergangene als antiquarischer Historiker; und nur der, dem eine gegenwärtige Not die Brust beklemmt, und der um jeden Preis die Last von sich abwerfen will, hat ein Bedürfnis zur kritischen, das heisst richtenden und verurteilenden Historie". Friedrich Nietzsche "Vom Nutzen und Nachteil der Historie für das Leben". Unzeitgemässe Betrachtungen Zweites Stück. En: Werke in zwei Bänden. München: Carl Hanser Verlag, 1967, Band I, 126. 
así su existencia tiene una disculpa, digamos una justificación -esto es lo que hoy se designa preferentemente como el auténtico sentido histórico". ${ }^{2}$

Una de las manifestaciones más extendidas de la época moderna sería, por consiguiente, la existencia de un sujeto carente de historia, y en este marco la escritura en general ya no constituiría un quehacer arqueológico que recupera y fija los monumentos, documentos o huellas del pasado (Ricoeur 1996: 804 y ss., III), sino una especie de mero ejercicio solipsista, según el cual sólo es posible conocer, sólo tiene existencia ontológica, aquello que se encuentra en la esfera temporal de lo inmediato.

Adicionalmente, podemos tomar en consideración el valor que adquiere la escritura en el tiempo como depósito de la memoria histórica. Si nos referimos al establecimiento del canon literario como producto de la decantación de una tradición, podemos precisamente hacer hincapié en el papel que desempeña el tiempo en este proceso al otorgar legitimidad a la obra de arte dentro del campo cultural. Una contribución a este ámbito de discusión es lo expresado por Foucault, quien al examinar el problema del texto como eventual documento, monumento o depósito de la historia afirma: "El documento no es el instrumento afortunado de una historia que fuese en sí misma y con pleno derecho 'memoria'; la historia es cierta manera, para una sociedad, de dar estatuto y elaboración a una masa de documentos de la que no se separa" (1970: 10). Y luego agrega: "En nuestros días, la historia es lo que transforma los documentos en monumentos [...], la historia tiende a la arqueología, a la descripción intrínseca del monumento" (id.: 11). De acuerdo con lo anterior, en la actualidad sólo sería posible conocer el presente de manera solipsista, y este, por añadidura, no reconoce anclaje en la tradición personal ni en la historia colectiva. Además, el texto contemporáneo es simple documento mientras no sea sancionado y consagrado como monumento por el transcurrir de la historia. ¿En qué medida es esto también válido para el texto ficcional? Es vasta la diversidad de respuestas que ha suministrado la teoría literaria, por ello es del caso dejar planteado el problema de los eventuales vasos comunicantes que pueden existir entre estas variables del problema.

\section{LA MEMORIA Y EL TIEMPO}

Le Goff señala que "[L]a memoria, como capacidad de conservar determinadas informaciones, remite ante todo a un complejo de funciones psíquicas, con el auxilio de las cuales el hombre está en condiciones de actualizar impresiones e informaciones pasadas, que él se imagina como pasadas" (1991: 131); entonces, el proceso de actualizar el pasado depende, en parte, de la capacidad de almacenamiento de la memoria, pero en mayor medida, dadas las voces que se escuchan en la actualidad sobre este punto, de la voluntad misma del hombre de actualizar ese pasado. Nos interesa destacar este último aspecto, por cuanto diversos filósofos y estudiosos de la materia han hecho hincapié en la circunstancia de que nuestra época, especialmente en el caso de las sociedades del primer mundo, vive desde fines de los años '70 inmersa en una

2 "Die entgegengesetzte Empfindung, das Wohlgefühl des Baumes an seinen Wurzeln, das Glück, sich nicht ganz willkürlich und zufällig zu wissen, sondern aus einer Vergangenheit als Erbe, Blüte und Frucht herauszuwachsen und dadurch in seiner Existenz entschuldigt, ja gerechtfertigt zu werden -dies ist es, was man jetzt mit Vorliebe als den eigentlich historischen Sinn bezeichnet" (id. 128). 
suerte de cultura de la memoria. Algunas manifestaciones de esta cultura en Europa y Estados Unidos serían la restauración historicista de centros urbanos; paisajes y pueblos convertidos en museos al aire libre; políticas de protección del patrimonio cultural fomentadas y llevadas a cabo por gobiernos u organizaciones no gubernamentales; la aparición de la moda retro en el marco de una cierta postmodernidad cooptadora de todo lo que sea pasado; el marketing masivo de la nostalgia; en fin, el aumento de documentales históricos e incluso de canales monoprogramáticos en la televisión por cable, como History Channel (Huyssen 2002: 18). No obstante, a la luz de este fenómeno no deja de ser paradójico que el mismo Huyssen destaque el hecho de que "[C]ada vez más, los críticos acusan a la cultura de la memoria contemporánea de amnesia, de anestesia o de obnubilación. Le reprochan su falta de capacidad y de voluntad para recordar y lamentar la pérdida de conciencia histórica" (2002: 22). Ante estos rasgos aparentemente antagónicos, mutuamente excluyentes y que apuntan en direcciones opuestas en relación con la situación actual de la memoria y el pasado, este autor busca una explicación en los siguientes términos:

...mi hipótesis es que intentamos contrarrestar ese miedo y ese riesgo del olvido por medio de estrategias de supervivencia basadas en una "memorialización" consistente en erigir recordatorios públicos y privados. El giro hacia la memoria recibe un impulso subliminal del deseo de anclarnos en un mundo caracterizado por una creciente inestabilidad del tiempo y por la fracturación del espacio en el que vivimos (24).

La tendencia actual consiste, hasta cierto punto, en practicar el ejercicio de crear un pasado ilusorio no vivido -más o menos correspondiente a aquello que Ricoeur llama historia dicha (1996: 942, III)-, sino que extraído de archivos ajenos, y consumido a la manera de una mercancía altamente perecible, dado que el ciclo vital de los objetos de consumo se ha reducido dramáticamente. Como resultado de esta tendencia, “...nos encontramos atrapados en un presente que cada vez se va achicando más, un presente del reciclaje a corto plazo con el único fin de obtener ganancias..." (Huyssen 2002: 28-9). El presente sobresaturado por el consumo de bienes culturales simbólicos (compárese esto con lo afirmado por Nietzsche en "De la utilidad..." respecto del hombre moderno que se satura de épocas) se "comporta" a la manera de un agente reductor de las otras dos dimensiones del tiempo, el pasado y el futuro, convirtiéndose el devenir histórico en una entidad meramente sincrónica y eliminándose así la diacronía.

Por consiguiente, resulta singularmente paradojal observar una dimensión temporal del presente de aparente espesor, llena de contenidos que simulan otorgarle profundidad, no obstante que en realidad operan como espejismos que producen finalmente en el hombre una sensación de orfandad y carencia de asidero, dado el carácter evanescente, provisional y transitorio de ese presente. Se trata de presuntos contenidos que absorben el pasado y el futuro y escenifican un espacio de presente, insistimos, en aparente expansión. Si esto es realmente así, entonces es pertinente interrogarse acerca de la justificación que puede esgrimir la memoria como depósito, almacén, archivo o cualquier metáfora que utilicemos. Pero si esto no es así, entonces tal vez todo apunta hacia una teoría de la conspiración, según la cual " [S]e ha querido dar vuelta pronto la página, como si la historia pudiese escribirse a punta de páginas inconclusas, relatos a medio terminar y cuentas sin saldar. No nos hemos 
dado el tiempo ni el coraje de la memoria. El olvido nos acecha. Nos hace creer que hemos cambiado, que ya no somos los mismos. Que podemos mirar hacia delante, sin mirarnos hacia adentro" (Milos 2000: 59). El acecho del olvido y la orfandad como mecanismo voluntario o involuntario de ajuste de cuentas con la memoria provocan en el individuo contemporáneo una profunda sensación de fragilidad respecto del pasado, especialmente cuando aquel constata que se puede prescindir de esta dimensión del tiempo, tal como le sucede a Brausen, protagonista de La vida breve de Juan Carlos Onetti, quien expresa: “...borro mi huella a cada paso, descubro que cada minuto salta, brilla y desaparece como una moneda recién acuñada, comprendo [...] que es posible vivir sin memoria y sin previsión" (1950: 104).

En la misma dirección apunta el diagnóstico de Lechner y Rojo en relación con el problema de la conservación de la memoria o con el intento de manipularla en la realidad chilena actual. Para Lechner, nuestra sociedad se encuentra en un estado de suspensión temporal que la lleva a parecer detenida en una especie de presente continuo -Mircea Eliade tal vez lo llamaría tiempo sagrado-. Esta sociedad ejerce por una parte la censura respecto del pasado, especialmente el reciente, y por otra el futuro es un espacio que debe ser ocupado por las iniciativas o los proyectos individuales (1998: 124-5). Dentro de este mismo tema, pero en un ámbito más global, Rojo sostiene: "La continua liquidación del pasado y la apuesta al presente como si este fuera sólo un momento de tránsito hacia el progreso futuro [...] es un rasgo no de la modernidad en general sino de la modernidad capitalista" (2000: 329). Finalmente, y en un área que, creemos, aproxima la teoría a la novelística de Gonzalo Contreras, anotamos lo que expresa Carlos Ossa acerca del tiempo y la memoria contemporáneos: “...el ayer es el patrimonio de los dolores y las pérdidas y el hoy la luz redentora de la tecnología y las finanzas. No se trata de una abundancia de olvidos, sino de una primacía de recuerdos sin densidad, de comentarios y fechas, pero sin preguntas, sin delirios" (2000: 343).

Desde una perspectiva similar, el presente conflictivo parece encontrar una expresión adecuada en aquello que Ricoeur denomina ucronía, concepto equivalente al de utopía, cuya manifestación consistiría en un desgarramiento entre dos huidas, “...la de un pasado superado y la de un último que no suscita ningún penúltimo asignable" (1996: 948, III). En este contexto "[E]l presente, así dividido en sí mismo, se refleja en 'crisis' [...] una de las mayores implicaciones de este presente nuestro" (ibíd.). Según Ricoeur, esta vertiente del tiempo respondería a una característica básica de la modernidad, la cual consiste en una restricción del espacio de la experiencia a tal punto, que hace que el pasado se perciba como más lejano a medida que parece más transcurrido. Y más adelante agrega: "El presente es por completo una crisis cuando la espera se refugia en la utopía y cuando la tradición se convierte en un depósito muerto" (1996: 980-1).

La crisis del presente señalada por Ricoeur y los demás filósofos y críticos revisados anteriormente podría manifestarse a través de un pasado sin huellas de relevancia en el presente, toda vez que en las novelas chilenas contemporáneas vistas como una totalidad el pasado parece adoptar desde la ausencia el estatuto de un agente que simula clausurar los posibles recuerdos y bloquear la memoria, sobreviniendo con ello el olvido, la afasia y el vacío emocional. En este sentido, el tiempo entendido como depósito de las experiencias vitales se presentaría como una subjetividad incapaz de ejercer magisterio sobre el presente, por lo cual los protagonistas de las novelas se 
verían restringidos a la experiencia inmediata cuando hacen la tentativa de acceder al conocimiento de sí mismos y a una verdad significativa para sus existencias. Por consiguiente, un análisis de esta narrativa permitiría constatar si el tiempo en los relatos de los '90 se presenta caracterizado por una falta de espesor tal, que en el nivel de la enunciación haría prácticamente innecesario el recurso a las anacronías como estrategia narrativa. En tales circunstancias sería válido preguntarse: cui bono memoria?

\section{ESCRITURA Y MEMORIA}

En su obra La diseminación, Derrida se refiere a la escritura como un fármacon que actúa sobre la memoria hipnotizándola, fascinándola, adormeciéndola y haciéndola salirse de sí en el monumento (1975: 157-8). A modo de comparación, recordemos la opinión que manifiesta en el Fedro en relación con el discurso escrito, al cual no considera precisamente un fármaco de la memoria, sino un simple recordatorio, una apariencia de sabiduría. Como se sabe, para este filósofo la escritura favorece el descuido de la memoria, y para él el discurso escrito tiene, además, mucho de juego. También recordemos, a propósito de la relación entre escritura y memoria, lo que señalaba Huyssen en referencia a nuestra época caracterizada por la cultura en gran proporción mercantilista de la memoria, y donde se intenta conjurar el espectro del olvido mediante la estrategia de la "memorialización", entendida esta como un constante "erigir recordatorios públicos y privados" (2002: 24).

En el acápite anterior anotamos algunas manifestaciones concretas de este proceso de "musealización" de la cultura, y en este agregamos otras que también forman parte del fenómeno en discusión, y que son especialmente atingentes al punto que desarrollamos aquí: la escritura de memorias, confesiones, autobiografías y novelas históricas. Los agentes del campo cultural con su función sancionadora, y la tradición y el tiempo con su efecto de sedimentación natural dictaminarán si estos tipos discursivos enderezados hacia la memoria lograrán completar el trayecto que conduce desde el documento al monumento, a partir del cual, como señala Derrida, eventualmente adormecerán, fascinarán y adormecerán la memoria.

No obstante, el panorama es más complejo de lo que a simple vista sugiere el intento de simplificar los términos para homologar el acto de la escritura con el ejercicio de la memoria. Es cierto que, como indica Muñoz Molina, "[E]n el acto de escribir, como en la conciencia diaria de cualquiera, inventar y recordar son tareas que se parecen mucho y de vez en cuando se confunden entre sí. La memoria está inventando de manera incesante nuestro pasado, según los principios de selección y combinación..." (2001: 311); empero, no es menos cierto que para otros pensadores e intelectuales el mundo contemporáneo experimenta una crisis profunda respecto de la memoria y de la identidad personal en una magnitud tal, que ha llevado a escritores como Piglia a expresar lo siguiente: "Los narradores contemporáneos se pasean por el mundo de Proust como Fabrizio en Waterloo: un paisaje en ruinas, el campo después de una batalla. No hay memoria propia ni recuerdo verdadero, todo pasado es incierto y es impersonal" (2004: 17). Para el argentino, vivimos en la actualidad la muerte de Proust narrativamente hablando, es decir, la muerte de la memoria en su función de cauteladora de la temporalidad. 
Mucho se ha especulado y escrito acerca de la crisis del lenguaje en general y de la escritura en particular en el transcurso de los dos o tres últimos siglos, y no es del caso multiplicar los ejemplos para ilustrar un fenómeno que se ha convertido en un tópico de carácter epistemológico. Acaso sea suficiente con hacer presente lo manifestado por Cortázar a través de la figura de Morelli en Rayuela, quien cree que la literatura está en crisis, que la palabra ha dejado de tener una función expresiva y que el signo ya no significa (2004). O bien podemos rescatar, desde los inicios del siglo XX, la conocida Carta de Lord Chandos de Hugo von Hofmannsthal, publicada en 1902, pero situada contextualmente en 1603, es decir, en el período de transición de finales de la era isabelina, y en la cual el remitente, Lord Chandos, expresa a su corresponsal Francis Bacon: "Todo se descomponía en partes, y cada parte en otras partes, y nada se dejaba ya abarcar con un concepto" (1996: 31). La atmósfera fin de siècle que denota la Carta... remite sinecdóticamente a todo un mundo que estaba en proceso centrífugo de descomposición, vale decir, al Imperio Austro-Húngaro y, más globalmente, a la Europa de la Belle Époque, como también lo atestiguaron, en el terreno del lenguaje, contemporáneos de Hofmannsthal como Fritz Mauthner o Ludwig Wittgenstein, ambos precisamente filósofos del lenguaje.

Esta conciencia frente a un lenguaje portador de un signo “...destituido de su carga cognoscitiva..." (Magris 1996: 14) sería reactualizada un siglo más tarde por Juan José Saer en la novela El entenado con palabras casi idénticas, pues mientras Lord Chandos alude a “...palabras que se me descomponían en la boca como hongos podridos...” (1996: 30), el narrador-protagonista de la novela de Saer dice: "En la boca, las palabras se me deshacían como puñados de ceniza, y todo parecía, en el día indiferente, desolador" (2004: 117). A ambos entonces, al entenado de comienzos del siglo XVI, y al Lord de comienzos del siglo XVII es aplicable lo expresado por Magris al comentar la Carta...: “...él no puede archivar ningún instante de su vida, todo sigue viviendo en él con un conflicto punzante que amenaza con hacer saltar las claves de su personalidad, por el exceso de contenidos desgarradores que llegan a abarcarse" (1996: 13).

Pero volvamos al inicio: si el lenguaje, si la escritura específicamente, no es capaz de dar cuenta de la realidad de manera adecuada, entonces todo intento de rescate del pasado mediante la memoria con su soporte tecnológico, el fármacon de la escritura, se convierte en una empresa azarosa y utópica. En este aspecto, recordemos una vez más las tribulaciones del narrador de "El Aleph" frente a la riqueza de la realidad y a las limitaciones de los signos para hacerle justicia. Sin embargo, no se trata necesariamente de que el escritor quede paralizado por la falta de significados, sino, por el contrario, de que la exuberancia polifónica del mundo contemporáneo provoca una cantidad tal de epifanías, que el lenguaje parece capitular e inclinarse finalmente por el silencio. Así lo perciben estos escritores separados por un siglo en el cual se produjo una explosión de los multimedia que contribuyó a aumentar exponencialmente los estímulos y mensajes que nos asaltan a cada momento, los cuales pueden llegar a constituir eventualmente un “...exceso de contenidos desgarradores...”, como citábamos en el acápite anterior, y por ello se presume que nuestro conocimiento de la realidad debiera aumentar igualmente de manera significativa.

Tal vez este aspecto, la explosión multimedia que se ha transformado a estas alturas en una especie de tópico intelectual, oculte uno de los términos de la paradoja que le ha correspondido experimentar a los escritores de finales del siglo XX, paradoja 
en la cual el otro de los términos es el proceso de universalización de los contenidos del mundo por la vía de la tan socorrida como vilipendiada idea de la globalización, fenómeno que va acompañado por la diversidad y dispersión de temáticas como rasgo constituyente de la narrativa de los años '90 en Chile. La supuesta globalización, empero, no es solamente un problema de superposición o trasvasije mecánico de contenidos de mundo desde los territorios de una mayor a los de una (aparente) menor densidad cultural; ni se trata de una especie de profecía autocumplida, sino que afecta además a la problematización en torno a la identidad local de los países afectados por el proceso. Respecto de este fenómeno dice el sociólogo Jorge Larraín:

Aunque es posible detectar elementos culturales de las más variadas procedencias, que tienden a romper con los límites nacionales y espacio- temporales y se van internacionalizando, esto no implica que la globalización vaya a significar una creciente homogeneización cultural ni que la cultura vaya a ir progresivamente desterritorializándose. Puede que hoy exista un cierto espacio cultural electrónico sin un lugar geográfico preciso, pero las culturas locales nunca perderán su importancia y lo global sólo puede actuar a través de ellas. Lo global no reemplaza a lo local, sino que lo local opera dentro de la lógica de lo global (2001: 41-2).

Globalización, o imbunchización de por medio, el cambio de siglo plantea diversos desafíos frente a las magnitudes y velocidades con que concebimos y percibimos el fenómeno temporal, ya sea a partir de una imagen impuesta desde los grandes centros de poder real o simbólico, desde una posición ecuménica o bien desde nuestras propias especificidades locales.

Volviendo al problema del tiempo en la novela, si lo que postulábamos más arriba no es mera hipótesis, si Piglia está en lo cierto, Proust, el sumo sacerdote del tiempo recobrado, está muerto para la contemporaneidad, por lo cual no debiéramos concebir la idea de hallar epígonos suyos entre los narradores de finales del siglo XX, es decir, entre los de la década del ' 90 en Chile, incluido Gonzalo Contreras, pues a la luz de lo que constatamos en los capítulos anteriores, el Zeitgeist imperante no demanda la recuperación (no mercantilista) del pasado, sino la toma de conciencia de la levedad de un tiempo congelado en el presente sin pre ni postludio. Consecuentemente, y como efecto colateral en lo que concierne a la narratología, no debiera tener mayor relevancia el hecho de que técnicamente todo relato posea una disposición in extrema res, es decir, que se inicie cuando la historia dicha ya ha sido vivida en la lógica del universo ficticio, pues de acuerdo con nuestra prognosis en una parte significativa de la narrativa de los '90 existe una tendencia a hacer sincrónico aquello que podría o debería ser diacrónico mediante la reducción del tiempo de la aventura referido al pasado. Y en consecuencia, la escritura servirá a otros fines, pero no tendrá -en estos narradores al menos- una función recuperadora, redescubridora o rememoradora de un pasado puesto en elipsis, cualesquiera que sean los motivos para ello. La escritura sería tan solo archivo, depósito, memoria del presente, es decir, en referencia a la verdad ella ya no es “...testigo de lo pasado...”, sino meramente “...ejemplo y aviso de lo presente...” (Quijote 1981: 52). 


\section{OBRAS CITADAS}

Cervantes, Miguel de. 1981. El ingenioso hidalgo Don Quijote de La Mancha (29ª edición). Madrid: Espasa Calpe.

Cortázar, Julio. 2004 (1963). Rayuela. Buenos Aires: Suma de Letras.

Derrida, Jacques. 1975, La diseminación. Madrid: Fundamentos.

Foucault, Michel. 1997 (1970). La arqueología del saber. México: Siglo XXI.

Hofmannsthal, Hugo von. Carta de Lord Chandos. 1996. Murcia: Colegio Oficial de Aparejadores y Arquitectos Técnicos, Consejería de Cultura.

Hopenhayn, Martin. 1994. Ni apocalípticos ni integrados. Aventuras de la modernidad en América Latina. Santiago: Fondo de Cultura Económica.

Huyssen, Andreas. 2002. En busca del futuro perdido. México: Fondo de Cultura Económica.

Larraín, Jorge. 2001. Identidad chilena. Santiago: LOM Ediciones.

Lechner, Norbert. 1998. "Modernización y democratización: un dilema del desarrollo chileno". Estudios Públicos $\mathrm{N}^{\circ} 70$, otoño, pp. 231-42.

Le Goff, Jacques. 1991. El orden de la memoria: El tiempo como imaginario. Barcelona: Paidós.

Magris, Claudio. 1996. Prólogo "La indecencia de los signos". En: Carta de Lord Chandos. Por Hugo von Hofmannsthal, pp. 9-16.

Milos, Pedro. 2000. "Memoria colectiva: entre la vivencia histórica y la significación". En: Memoria para un nuevo siglo: Chile, miradas a la segunda mitad del siglo XX. (M. Garcés, P. Milos et al. Santiago: LOM Ediciones, pp. 43-76.

Muñoz Molina, Antonio. 2001. "El personaje y su modelo”. En Enric Sullá (ed.). Teoría de la novela-Antología de textos del siglo XX. Barcelona: Crítica, pp. 311-7.

Nietzsche, Friedrich. 1967. "Vom Nutzen und Nachteil der Historie für das Leben”. Unzeitgemässe Betrachtungen, Zweites Stück. En: Werke in zwei Bänden. München: Carl Hanser Verlag, 1967, Band I, pp. 113-174. (Traducción anónima en Internet: "De la utilidad y de los inconvenientes de los estudios históricos para la vida" www.elabedul.net/Documentos/ De_la_utilidad.doc.).

Onetti, Juan Carlos. 1950. La vida breve. Buenos Aires: Sudamericana.

Ossa, Carlos. 2000."La memoria de las equivalencias". En Memoria para un nuevo siglo: Chile, miradas a la segunda mitad del siglo XX, pp. 343-5.

Piglia, Ricardo. 2004. “La memoria ajena”. El malpensante 55. Junio 16-julio 31, pp. 16-18.

Ricoeur, Paul. 1996. Tiempo y narración. México: Siglo XXI, vol. II y III.

Rojo, Grínor. 2000. "Negación y persistencia de la memoria". En Memoria para un nuevo siglo: Chile, miradas a la segunda mitad del siglo XX, pp. 323-332.

Saer, Juan José. 2004. El entenado. Buenos Aires: Seix Barral, $4^{\mathrm{a}}$ ed. 